Egypt. Acad. J. Biolog. Sci., 4(1):9-18 (2012)

Email: egyptianacademic@yahoo.com

Received: $15 / 2 / 2012$
C. Physiology \& Molecular Biology

ISSN: 2090-0767

www.eajbs.eg.net

\title{
Studies of based sexual selection and male reproductive performance on the offspring fitness in Drosophila melanogaster
}

\author{
Abolhasan Rezaei $^{1}$ and Sheyda Akhshabi ${ }^{2}$ \\ 1- Department of Genetics-School of Basic Science, Islamic Azad University \\ Tonekabon Branch,Iran. \\ 2- Young Researchers Club, Tonekabon Branch, Islamic Azad University, \\ Tonekabon, Iran. \\ a.rezaei@tonekaboniau.ac.ir
}

\begin{abstract}
The fruit fly Drosophila melanogaster has short time life span, these flies, are particular advantage for ageing work, including, life history which divided up into distinct, morphological stages so that the period growth and development can be readily distinguished from the sexual mature ageing adult phase. Sexual selection aging means differential reproduction owing variation in the ability to obtain mates and fertilized oocytes. A few experimental studies have shown that the optimum strategy for males is often to mate with as many females as possible, whereas the optimum strategy for females is likely to select the most attractive male. As a result the mating males to females, the repetitive of mating is very important on the rate of fertility of females, if males has been twice mating by females usually the fertility will be decreased, here the function some secretion from ejaculate of males is very important. Recently the performance of male accessory gland proteins (Acps) were found in Drosophila melanogaster. Acps have been observed cause of increasing female oviposition rates, also increasing the rate of fertility, hatchability, son mating ability, mediate sperm storage, cause part of the survival cost mating male to females, may protect reproductive tracts or gametes from microbial attack, and also hundreds function known and unknown on the reproductive performance in males and females. However, until to date were found almost 25 to 150 proteins in male accessory glands, but also still were not distinguished function of all those proteins. Supporting these hypotheses, here we study the function of ageing on the rate of male sexual secretion and reproductive performance in offspring fitness. The objective of the current study is two-fold: the first aim is to evaluate mechanisms of sexual selection on the age affective in parental traits and second aim, is to evaluate mechanisms of sexual selection on the offspring fitness traits for their potential explained by random mating in the species Drosophila melanogaster.
\end{abstract}

Keywords: Drosophila melanogaster, Sexual selection, Accessory gland proteins, Male reproductive performance.

\section{INTRODUCTION}

Why use Drosophila melanogaster for reproductive performance and sexual selection:

The fruit fly Drosophila melanogaster is one of the most common genetic model organisms used for examining complex biological phenomena (Hall, J.C., Siegel, R.W.,
Tompkins, L. Kyriacou, C.P., 1980; Hall, J.C. 1978; Hall, J.C. 1979; Gilbert, 1981 and 1982; Sturtevant, 1915). The benefits of using Drosophila for studying sexual selection in particular include (a) its relatively short life span (almost 2-3 months), (b) easy of maintenance, (c) environmental and genetic manipulations that alter life span, (d) already available 
information on the sexual selection and mating behavior and also there are easy facility for doing experimental population genetics and behavior genetics (e) availability of stocks containing altered genes, (f) powerful molecular genetics techniques, sequence of the full Drosophila genome, and $(\mathrm{h})$ proven success in dissecting apart complex biological phenomena such as development (Clancy, D.J., Gems, D. Harshman, L.G. Oldham's, Stocker, H, et al., 2001). Population Drosophila melanogaster. Additional aspects of the biology of the fly that are of particular advantage for aging work include its life history, which is divided up into distinct morphological stages, so that the periods of growth and development can be readily distinguished from the sexually mature "aging" adult phase.

What is Sexual selection? The theory sexual selection actually is conflict between the evolutionary interests of the two sexes including male and female in animals and plants (Parker 1979) which comes about genetic differences, genetic drift, behavior of genetics, reproductive performance in male and female. (Arnqvist and Rowe 2005). Recently, sexual selection has attained widespread recognition as an engine of speciation, perhaps the most important of the forces that generates new species. Nathalie Luck and Dominique Joly (2005), were discussed, that; (1) sexual immaturity precludes mating in both sexes; (2) virgin females do not discriminate between sperm-loaded and sperm - depleted males, and (3) males mate preferentially with virgin females, because inseminated females fend off the male, which tended to bring male courtship to an end. Female remating so was limited, but increased significantly when the first male was sperm-depleted. (Swanson et al., 2001a; Swanson et al., 2002; Swanson et al., 2004). Sexual selection also is deferential reproduction owing variation in the ability to obtain mates and fertilized oocytes. (Kaufman, B. P., and Demerc, M. 1942). The researches of sexual selection is limited to a few study organisms, most of them insects.

\section{Factors influencing on sexual selection:}

Mate choice may be exercised by either sex; however, females are generally choosier than males because they invest more in their gametes. (Jennions, M.D., 1997). Female choice is often based on direct benefits, such as better reproductive output, whereas male choice appears to be based on differences in female fecundity. (Spieth, H.T.,1952; Tram and Wolfner, 1998; Tram and Wolfner, 1999). However, when gamete production is limited, sexual selection theories predict that mate choice will be decisive for reproductive success in both sexes (Johnson et al., 1987). A few experimental studies have shown that the optimum strategy for males is often to mate with as many females as possible, whereas the optimum strategy for females is likely to select the most attractive male. (Gwynne, 1984; Pizzari, 2003). Mate choice by females has been demonstrated in many species (Anderson, 1994), and the most important signals used in mating recognition are based on an assessment of visual, acoustic or chemical characteristics of the male phenotypes (Kaufman, B.P. and Demerec, M. 1942). However, in some other species complete role reversal has been observed. With choosy male and competitive females. (Bondurinsky, 2001). Sexual selection theory states that the relative parental investment of males and females changes the relative availability of the sexes as mates (operational sex ratio) (Heifetz and Wolfner, 2004; Luck, 2005). Thereby changing their posterities rate of reproduction, and that parental investment is the important factor in determining which sex gains more by mating multiple times. Because the overall level of parental investment determines the population growth rate. 
Any parental investment by one sex is potential available to members of the opposite sex. (Trivers, 1972). To evolve toward an optimum, younger individuals may have higher current fitness because they will be closer to the current selective optimum than older individuals. Hansen and Price (1995), discussed that there were reduced breeding values for the 5 week old males in two of the three fitness components we investigated (albeit only one of the these, egg-to-adult survival, was statistically significant). There was no evidence for any difference in the three fitness measures between the 2 day old and the 2 week old males. The effects on the oldest males are not large: from young to old the best estimate is about $3 \%$ reduction egg - to adult survival and $4 \%$ reduction in son mating ability (Anderson, 1994). The different conclusions reached by Hansen and Price (1995) and Kokko and Lindstrom (1998) may be a result of the different approaches they used to model female preference based on male age. Hansen and Price (1995) assumed a trade-off between early and late life fitness components. In contrast, Kokko and Lindstrom (1998) assumed that such trade-offs may not exist and that individuals may differ in genetic quality, leading to increased survival and fecundity of higher-quality individuals at all ages. Although it is probably that individual males in a population differ in genetic quality, Kokko and Lindstrom (1998) examined only the evolution of female preference for older males and did not test whether female preference for young or intermediate age males could evolve. Therefore, it is not clear that the results of Kokko and Lindstrom (1998) and Kokko 1998, rule out the conclusions of Hansen and Price. To examine whether female preference for young and intermediate age males could evolve when males differ in genetic quality. Sperm Competition, the competition between sperm from two or more males for the fertilization of a female's eggs, frequently results in the differential utilization of sperm from different ejaculates (Parker, 1970). This can have significant effects on male fitness. Sperm precedence refers to the proportion of progeny from a multiply-mated female that are fathered by each male. The preponderance offspring from the last male has been termed sperm displacement or sperm predominance. The latter term is preferred since it implies no mechanism (Gromko et al., 1984). From fertility fitness perspective the highest male fitness would be the genotype that maximizes the number of offspring fathered regardless of the order of mating. If we assume that multiplymated females have mated with only two males, the total sperm competition fitness component for males is dependent on three parameters; $\mathrm{P}^{\prime}, \mathrm{P} 1$ and $\mathrm{P} 2$. $\mathrm{P}^{\prime}$ is the number of offspring fertilized by a male genotype before the female remates. P1 and $\mathrm{P} 2$ are the proportion of offspring fertilized by a male genotype after a female remates; P1 when he was the first male and P2 when he was the second, (Gromko et al., 1984, Turner and Anderson, 1983). From a fitness perspective the important parameter is the total of all three, which give an average number of offspring fertilized by a particular male genotype.

\section{Parental age influenced on offspring fitness in Drosophila melanogaster :}

Parental effects may play a crucial role in the evolution of aging. In studies by (Rose et al., 1984), was showed, that offspring viability declines with parental age, older files produce less viable offspring. Indeed, found that advanced parental age reduces the longevity of offspring, often with stronger effects on daughter than sons. (Gromko M.H., Markow T.A., 1993). In addition to effects on longevity, single-generation studies have found that maternal age also influences the length of development, egg-to-adult viability and heritability of 
morphological traits (Parsons, 1996; Mills and Hartmann- Goldstein, 1985; Fox, 1993; Mousseau, 1991). Promislow et al., 2003, found that maternal and paternal age also influences the rate of increase in age-specific mortality and the level of age-independent mortality of offspring. And older mothers produce shorter-lived offspring. Furthermore, they found that the maternal age effects were much more pronounced on daughters than on sons. (Promislow et al., 2003). Conversely, paternal age effects were significantly greater on sons than daughters. So, in multiple generation studies conducted after 1967, advanced parental age typically increased longevity in fruit flies (Wattiaux, 1968; Rose and Charlesworth, 1981; Luckinbill, et al., 1984; Rose, 1984; Luckinbill and Cloare 1985; Partridge and Fowler., 1992; Services, 1985; Chippindale, et al., 1994).

\section{Male accessory gland secretions:}

Drosophila melanogaster, during the mating by male to female transfer a collection of specialized proteins, secreted by male accessory glands along with sperms. (Monsmsa and Wolfner 1988). The accessory gland protein has been many function that including, sperm surviving in female genital tract, increasing in reproductive performance, such as, fecundity(the rate of egg laid) and fertility ( the egg of hatchability), the effect of the mated female's physiology and behavior (RaviRam and Ramesh 2003; Chen 1996). There are similarity studies about male accessory gland proteins (Acps) (reviewed in Chapman et al., 1988 and Chapman et al., 1995). Studies regards Acps were observed that not only to increase female oviposition rates (Heifetz et al. 2000), facilitate sperm storage (Neubaum \& Wolfner 1999; Chapman et al., 1995), and incapacitate sperm from previous males (Harshman and Prout, 1994; Prout and Clark, 2000), but also to reduce mating receptivity (Manning, 1962; Leopold et al., 1971; Obata, 1988; Eady, 1995; Miyatake et al., 1999).Studies about sperm storage also are shown that sperm storage is an important process in the male mating ability and reproduction performance in animals, including insects and mammals. In Drosophila, from accessory gland secretion subset proteins generated and transferred from the accessory gland of the male reproductive tract that famous 'Acps', is essential for sperm storage. (Wolfner, 2009). However, after mating the few sperm that they do store are not used for fertilization, so the function of sperm storage is very important. (Wolfner, 2009).

Also the researches are shown the accessory reproductive glands (ARG) of male insects produce secretions essential for the transfer of sperm to the female, when transferred during mating, these molecules exert wide-ranging effects and female reproductive activity and they improve the male's chances of siring a significant proportion of the female's offspring. It synthesizes and secrets a complex mixture of proteins, amino acids and carbohydrates that form part of the seminal fluid which is transferred to the female at the time of mating.(Wolfner et al., 1997; Ravi Ram and Wolfner, 2007 a,b; Monsma and Wolfner, 1988; Monsma, 1990; Nakayama, 1997). Mated females in Drosophila exhibit a variety of physiological and behavioral changes in reproductive status, aside from their obvious production of offspring (Wolfner et al., 1997). Their egg-laying rate increases after a normal (15-20min) copulation; they mobilize mechanisms to store sperm in specialized reproductive organs. Female that have copulated are less attractive courtship objects than they were per-mating; when they are courted, they block a male's copulation attempts by extruding their ovipositor. These changes that occur in mated females are caused in part by seminal substances (accessory gland proteins (Acps), that are 
transmitted to them by their mate (Wolfner, 1997, 2002). Between 25-150 Acps were initially thought to be transferred to the female during mating. (Singh, 2000; Singh, 1990; Singh and Kulthinal, 2000; Wolfner et al., 1997). Genetic analysis has revealed the functions of four Acps that far. Acp 26 $\mathrm{Aa}$ (ovulin) is a prohormone that triggers on increase in ovulation rate (Heifetz et al., 2000, Wolfner, 2005). Acp36DE is a glycoprotein that is essential for sperm storage (Neubaum and Wolfner 1999 a and $b)$. By regulating sperm accumulation into storage (Blouch qazi and Wolfner, 2003). Acp62f is a trypsin and has been suggested to preserve sperm viability (Lung et al., 2002). However, nothing will be know about accessory gland proteins to analysis by way of SDS-PAGE and enzymes to understand the nature and extent of pattern differentiation among various members of the Drosophila melanogaster, as well as the pattern of inheritance of these proteins in the offspring progeny. The protein function can be readily separated from eight to ten major bands. (StummZolinger and Chen, 1984; Chen, 1988; Chapman, 1995; Chapman and Wolfner, 1988; Obata, 1988; O'Dell, 2003). The fraction of these proteins for two other ejaculate proteins has been discovered, including esterase 6 also and low molecular weight peptide that stimulates female oviposition (Tompkins and Richmond, 1983).

\section{Studies of enzymes activity in Drosophila melanogaster:}

Despite more than a decade of research, the evolutionary significance of molecular variants of enzymes in Drosophila and other organism is far from clear. Recently several workers have stressed that a new research strategy is needed which will integrate finding on the biochemistry and physiology of enzyme variants with observed changes in allele frequencies in natural populations. (Clark, 1971). The product of this locus $\alpha$ and $\beta$ esterase, has recently been identified as a male reproductive enzyme based on its localization in the adult male anterior ejaculatory duct (Sheehan, Richmond and Cochrane 1979). Its transmission to females in the ejaculate and its effect on the timing of remating in females (Richmond et al., 1976).

In this project, I will be compare ejaculate competitive ability of offspring males for $\alpha$ and $\beta$ esterase alleles, in natural population Drosophila melanogaster.

\section{CONCLUSION}

In this study we performed the effective of sexual selection and mating behavior from male and female of Drosophila melanogaster on the fitness traits in the during mating. Sexual selection the basis of many aspect those are the males and females of most species have conflicting strategies for maximizing the number of offspring, in Drosophila, the contributed between sexual selection and survival of the offspring fitness, that related to sexual secretion by males.(Andersson 1994;Birkhead, 2000) This study suggested that there are variation on the rate of secretion seminal fluid protein from accessory gland, related to male age classes (young, middle and old aged). Therefore, young flies more generated Acps, that the cause of increasing reproductive performance and physiological behavior in males and females, such as, male mating ability, courtship activity in males and fecundity, fertility, female receptivity and also offspring fitness in females. Here in our laboratory, we are doing on the Acps experiments, including, the effect of male age on the offspring fitness, reared male in different temperatures on the offspring fitness and the rate of relationship between parental reproductive performance with accessory gland proteins, in future will be published. 


\section{ACKNOWLEDGMENTS}

This work had financially supported by the Research Council of Islamic Azad University Tonekabon branch.

\section{REFERENCES}

Arnqvist, G. and Rowe, L. (2005): Sexual conflict. Princeton, NJ: Princeton University Press.

Anderson. (1994): Sexual selection. Princeton, NJ: Princeton University Press.

Birkhead T, (2000). Promiscuity: An evolutionary history of sperm competition. Harvard Univ. Press, Cambridge, MA.

Bloch Qazi, M. C.; Hiefetz, Y. and Wolfner MF. (2003): The developments between gametogenesis and fertilization: ovulation and female sperm storage in Drosophila melanogaster. Dev Bio., 256: 195-211.

Bonduriansky R. (2001): The evolution of male mate choice in insects: a synthesis of ideas and evidence. Biolog.Rev.,76: 305-339.

Chapman, T.; Liddle LF.; Kalb, JM.; Wolfner, MF. and Partrifge, L. (1995): Cost of mating in Drosophila melanogaster female is mediated by male accessory gland products. Nature. 373: 241-244.

Chapman, KB. and Wolfner, MF. (1988): Determination of male-specific gene expression in Drosophila accessory glands. Dev Biol. 126: 195-202.

Chen, PS.; Stumm-Zollinger, E.; Aigaki, T.; Balmer, J.; Bienz, M. and Bohlen, P. (1988): A male accessory gland peptide that regulated reproductive behavior of female Drosophila melanogaster. Cell., 54: 291-298.

Chen, PS. (1984): The functional morphology and biochemistry of insect male accessory glands and their secretions. Annul Rev. Entomol .20: 233-255.
Chen, PS. (1996): The accessory gland proteins in male Drosophila: structural, reproductive, and evolutionary aspects. Experientia 52: 503-510.

Chippindale, AK.; Hoang, DT.; Service, PM. and Rose MR. (1994): The Evolution of development in D.melanogaster selected for postponed senescence. Evolution. 48: 1880-1899.

Clark, AG. Aguade, M.; Prout, T.; Harshman, LG. and Perotti, ME. (1971): Microtubules as components of Drosophila. Langley, Variation in sperm displacement and its associamale paragonia secretion: an electron microscopic study, with accessory gland protein loci in Drosophila melanogaster enzymatic tests. J. Submicrosc. Cytol., 3: 255-282.

Clancy, DJ.; Gems, D.; Harshman, LG.; Oildman, S.; Stocker, H.; Hafen, E.; Leevers, SJ. and Partridge L. (2001): Extension of life-span by loss of CHICO, a Drosophila Insulin Receptor Substrate Protein. Science., 292: 104-106.

EADY P E. (1995): Why do male Callosobruchus maculatus beetles inseminate so many sperm? Behav. Ecol. Sociobiol. 36: 25-32.

Fox c, W. (1993): The influence of maternal age and mating frequency on egg size and offspring performance in Callosobruchus maculatus. Oecologia 96:139-146.

Gilbert, DG.; Richmond, RC. and Sheehan, K. (1981): Studies of esterase 6 in Drosophila melanogaster Progeny production and sperm use in females inseminated by males carrying active or null alleles. Evolution., 35: 21-37.

Gilbert, DG. and Richmond, DG. (1982): Esterase-6 in Drosophila melanogaster reproductive function of active and null mates at low temperature. Proc. Natl. Acad. Sci. USA. 79: 2962-2966. 
Gilbert, DG. (1981): Ejaculate esterase 6 and initial sperm use by female Drosophila melanogaster. J. Insect Physiol. 27: 641-650.

Gromko, MH.; Gilbert, DG. and Richmond, RC. (1984): Sperm transfer and use in the multiple mating system of Drosophila. In: Smith RL, editor. Sperm Competition and the Evolution of Animal Mating Systems, 371-426. New York: Academic Press.

Gwynne, DT. (1984): Courtship feeding increases female reproductive success in bushcrikets. Nature. 307:361-363.

Gromko, MH. and Markow, TA. (1993): Courtship and remating in field populations of Drosophila. Animal Behavior. 45:253-262.

Hansen, TF and Price, DK. (1995): Good genes and old age, do old mates provide superior genes? Evolution biology. 8: 759-778.

Hall, JC.; Siegel, RW.; Tompkins, L. and Kyriacou, CP. (1980): Neurogenetics of courtship in Drosophila. Stadler Symp. 12: 43-82.

Hall, JC. (1978): Courtship among males due to a male-sterile mutation in Drosophila melanogaster. Behav. Genet. 8: 125-41.

Hall, JC. (1979): Control of male reproductive behavior by the central nervous system of Drosophila: dissection of a courtship pathway by genetic mosaics. Genetics. 92:437-57.

Heifetz, Y.; Lung, O.; Frongillo, EA. and Wolfner, MF. (2000): The Drosophila seminal fluid protein Acp26Aa stimulates release of oocytes by the ovary. Current Biology., 10: 99-102.

Heifetz, Y. and Wolfner, MF. (2004): Mating seminal fluid components, and sperm cause changes in vesicle release in the Drosophila female reproductive tract. Proceedings of the National Academy of Sciences. USA. 101: 6261-6.
Harshman, LG. and Prout, T. (1994): Sperm displacement without sperm transfer in Drosophila melanogaster. Evolution 48: 758-766.

Jennions, MD. and Petrie M. (1997): Variation in mate choice and mating preferences: a review of causes and consequences. Biological Reviews of the Cambridge Philosophical Society.72: 283-327.

Johnson, TE. (1987): Aging can be genetically dissected into component processes using long-lived lines of Caenorhabditis elegans. Proc. Natl. Acad. Sci. USA. 84: 3777-3781.

Kaufman, BP. and Demerec, M. (1942): Utilization of sperm by the female Drosphila melanogaster Am. Nat. 76: 445-469.

Kokko, H. and Lindstrom, J. (1996): Evolution of female preference for old mates. Proc. R. Soc. Lond. B 263: 1533-1538.

Kokko, H. (1998): Good genes, old age and life-history trade-offs. Evolutionary Ecology. 12: 739-750.

Lung, O.; Tram, U.; Finnerty, C.; EipperMains, M.; Kalb, JM. and Wolfner, MF. (2002): The Drosophila melanogaster seminal fluid protein Acp62F is a protease inhibitor that is toxic upon ectopic expression. Genetics (in press).

Luck, N. and Joly, D. (2005): Sexual selection and mating advantages in the giant sperm species, Drosophila bifurca. J. Insect Sci., 5(10): 1-8.

Lubkinbill, L.; Arking, R.; Clare, MJ.; Cirocco, WC. and Buck, S. (1984): Selection of delayed senescence in Drosophila melanogaster. Evolution .38: 996-1003.

Luckinbill, L. and Clare, MJ. (1985): Selection for life span in Drosophila melanogaster. Heredity. 5: 9-18.

Leipold, R A.; Terranova, A C. and Swilley, E M. (1971): Mating refusal in Musca domestica: effects of repeated mating and deceleration upon frequency and duration of 
copulation. J. Exp. Zool. 176: 353359.

Manning, A. (1962): A sperm factor affecting the receptivity of Drosophila melanogaster females. Nature. 194: 252-253.

Miyatake, T.; Chapman, T. and Partridge, L. (1999): Mating induced inhibition of remating in female Mediterranean fruit flies Ceratitis capitata. J. Insect Physiol. 45: 1021-1028.

Mills, A. and Hartmann-Gildstein I. (1985): Maternal age, development time, position effect variegation in Drosophila melanogaster. Genet. Select. Evol. 17: 171-178.

Mousseau, TA. and Dingle, H. (1991): Maternal effects in insect life histories. A. Rev. Entomol. 36: 511534.

Monsma, SA.; Harada, HA. and Wolfner MF. (1990): Synthesis of two Drosophila male accessory gland proteins and their fate after transfer to the female during mating. Dev Biol., 142: 465-475.

Monsma, SA. and Wolfner MF. (1988): Structure and expression of a Drosophila male accessory gland gene whose product resembles a peptide pheromone precursor. Genes Dev. 2: 1063-1073.

Nakayama, S.; Kaiser, K. and AIGAKI K. (1997): Ectopic expression of sex peptide in a variety of tissues in Drosophila females using the $\mathrm{P}$ [GAL4] enhancer-trap system. Mol. Gen. Genet. 254: 449-455.

Neubaum, DM. and Wolfner MF. (1999):

Drosophila females require a seminal fluid protein, Acp36DE, to store sperm efficiently. Genetics. 153: 845-857.

Neubaum, DM. and Wolfner, MF. (1999a): Wise, winsome, or weird? Mechanisms of sperm storage in female animals. Curr. Top. Dev Biol. 41: 67-97.

Neubaum, DM and Wolfner, MF. (1999b): Mated Drosophila melanogaster females require a seminal fluid protein, Acp36DE, to store sperm efficiently. Genetics 153: 845-857.

Obata, S. (1988): Mating refusal and its significance in females of the ladybird beetle, Harmonia axyridis. Physiol. Entomol. 13: 193-199.

O'dell KMC. (2003): The voyeurs' guide to Drosophila melanogaster courtship. Behavioral Process 64:211-223.

Parker, GA. (1970): Sperm competition and its evolutionary consequences in the insects Biol. Rev. 45: 525-567.

Parker, GA. (1979): Sexual selection and sexual conflict in sexual selection and reproductive competition in insects (ed. M.S. Blum\& N.A. Blum. 123166. New York: Academic Press.

Promislow, DEL. (2003): Mate choice, sexual conflict and evolution of senescence. Behavior Genetics 33: 191-201.

Parsons, P A. and Kaul, D. (1966): Mating speed and duration of copulation in Drosophila pseudobscura. Heredity. 21: 219-225.

Partridge, L. and Fowler, K. (1992): Direct and correlated responses to selection on age at reproduction in $D$. melanogaster. Evolution. 46: 76-91.

Pizzari, T. (2003): Food, vigilance, and sperm: the role of male direct benefits in the evolution of female preference in a polygamous bird. Behavioral Ecology 14:593-601.

Prout, T. and Clark, AG. (2000): Seminal fluid causes temporary reduced egg hatch in previously mated females. Proc. R. Soc. Lond. B 267: 201-203.

Ravi Ram K. and Wolfner, MF. (2007a): Seminal influence: Drosophila Acps and the molecular interplay between males and females during reproduction. Integr. Comp. Biol. 47: 427-445.

Ravi Ram K. and Ramesh S. R. (2003): Male accessory gland proteins in 
Drosophila: a multifaceted field. Ind. J. Exp. Biol. 41: 1372-1383.

Ravi Ram K. and Wolfner MF. (2007b): Sustained post-mating response in Drosophila melanogaster requires multiple seminal fluid proteins. PLOS Genet. 3,e 238. doi: 10.1371/Journal.pgen.0030238.

Richmond RC. (1976): Frequency of multiple insemination in natural populations of Drosophila. American Natur. 110: 485-486.

Rose, MR. and Charlesworth, B. (1981): Genetics of life-history in $D$. melanogaster II, exploratory selection experiment. Genetics. 97: 187-196.

Rose, M R.; Doreyml.; Coyle AM. and Service; PM. (1984): morphology of postponed senescence in Drosophila melanogaster. Can. J. Zool. 62: 15761580

Service, P.; Hutchinsonm, M EW.; Mackinley, D and Rose MR. (1985): Resistance to environmental stress in Drosophila melanogaster selected for postponed senescence. Physiol. Zool. 58: 380-389.

Singh, BN. (2000): Drosophila ananassae: a species characterized by several unusual genetic features Curr. Sci. 78: 391-398.

Singh, RS. (1990): Patterns of species divergence and genetic theories of speciation. 231-265.

Singh, RS. and Kulathinal RJ. (2000): Sex gene pool evolution and speciation : a new paradigm. Genes Genet. Syst. 75: 119-130.

Sturtevant, A. (1915): Experiments on sex recognition and the problem of sexual selection in Drosophila. J. Animal Behavior. 5: 351-366.

Stumm-Zollinger, E. and Chen PS. (1985): Protein metabolism of Drosophila melanogaster male accessory glands. I. Characterization of secretary proteins. Insect Biochem. 15: 375-383.
Swanson, WJ.; Clark, AG.; WaldripDail., H.M.; Wolfner MF. and Aquardo, CF. (2001a): Evolutionary EST analysis identifies rapidly evolving male reproductive proteins in Drosophila. Proc. Natl. Acad. Sci. USA. 98: 7375-7379.

Swanson, WJ. and Vacquier, VD. (2002): The rapid evolution of reproductive proteins, Nat. Rev. Genet. 3: 137144.

Swanson, WJ.; Wong, A.; Wolfner, MF. and Aquardo, CF. (2004). Evolutionary expressed sequence tag analysis of Drosophila female reproductive tracts identifies genes subjected to positive selection. Genetics 168: 1457-1465.

Spieth, HT. (1952): Mating behavior within the genus Drosophila (Diptera). Bulletin American Museum National History 99:395474.

Sheehan, K.; Richmond, B. and Cochrane, J. (1979): Studies of esterase 6 in Drosophila melanogaster. The developmental pattern and tissue distribution. Insect Biochem. 9: 443-450.

Tompkins, L.; Hall, JC. and Hall, LM. (1980): Courtship-stimulating volatile compounds from normal and mutant Drosophila. J. Insect Physiol. 26:689-97

Trivers, RL. (1972): Parental investment and sexual selection. In: Campbell B, editor. Sexual Selection and the Descent of Man. Aldine, Chicago.

Tram, U. and Wolfner, MF. (1998): Seminal fluid regulation of female sexual attractiveness in Drosophila melanogaster. Proc Natl Acad Sci. USA. 95: 4051-4054.

Tram, U. and Wolfner, MF. (1999): Male seminal fluid proteins are essential for sperm storage in Drosophila melanogaster. Genetics. 153: 837-844.

Turner, ME. and Anderson, WW. (1983): Multiple mating and female fitness in 
Drosophila

Evolution 37: 714-723.

Turner, ME. and Anderson, WW. (1984):

Sperm predominance among

Drosophila pseudoobscura

karyotypes. Evolution. 38: 983-995.

Wolfner, MF. (1997): Tokens of love:

functions and regulation of

Drosophila male accessory gland products. Insect Biochem. Mol. Biol. 27: 179-92.

Wolfner, MF. (2002): The gifts that keep on giving: physiological functions and evolutionary dynamics of male seminal proteins in Drosophila. Heredity 88, 85-93.

Wolfner, MF.; Applebaum, S. and Heifetz, Y. (2005): Insect gonadal glands and their gene products. In Comprehensive insect physiology, pharmacology and molecular biology. biology (eds L. Gilbert, K. Iatrou \& S. Gill), 179-212. Amsterdam, The Netherlands: Elsevier.179-212.

Wolfner, MF.; Harada, HA.; Bertram, MJ.; Stelick, TJ.; Kraus, KW.; Kalb, JM.; Lung, YO.; Neubaum, DM.; Park, M. and Tram U. (1997): New genes for male accessory gland proteins in Drosophila melanogaster, Insect Biochem. Mol. Biol.27: 825-834.

Wolfner, M.F. (2009) Battle and ballet: molecular interactions between the sexes in Drosophila. J. Hered., 100:399-410.

Wattiaux JM. (1968): Cumulative parental effects in $D$ subobscura. Evolution. 22: 406 - 421. 